\begin{tabular}{|l|l|l||}
\hline \multicolumn{2}{|c|}{ PublisherInfo } \\
\hline \hline PublisherName & $:$ & BioMed Central \\
\hline \hline PublisherLocation & $:$ & London \\
\hline \hline PublisherImprintName & $:$ & BioMed Central \\
\hline \hline
\end{tabular}

\title{
Plant duplications
}

\begin{tabular}{|l|l|l||}
\hline \multicolumn{2}{|c|}{ ArticleInfo } \\
\hline \hline ArticleID & $:$ & 3866 \\
\hline \hline ArticleDOI & $:$ & $10.1186 /$ gb-spotlight-20001215-03 \\
\hline \hline ArticleCitationID & $:$ & spotlight-20001215-03 \\
\hline \hline ArticleSequenceNumber & $:$ & 303 \\
\hline \hline ArticleCategory & $:$ & Research news \\
\hline ArticleFirstPage & $:$ & 1 \\
\hline \hline ArticleLastPage & $:$ & 2 \\
\hline \hline & $:$ & RegistrationDate : 2000-12-15 \\
ArticleHistory & $:$ & OnlineDate $: 2000-12-15$ \\
\hline \hline ArticleCopyright & $:$ & BioMed Central Ltd2000 \\
\hline \hline ArticleGrants & $:$ & \\
\hline \hline ArticleContext & $:$ & 130591111 \\
\hline \hline
\end{tabular}




\section{William Wells}

Email: wells@biotext.com

In the 15 December Science, Vision et al. find that four large-scale duplication events, followed by gene loss, have shaped the Arabidopsis genome (Science 2000, 290:2114-2116). The duplication events are identified by first delineating 103 duplicated blocks containing seven or more genes. These duplicates are then assigned an age based on the sequence divergence between copies. The duplicates fall into four main age groups, all dating to the Mesozoic era (65 to 245 million years ago), which was a period when the angiosperms were diversifying. This analysis will help the process of lining up homeologous regions in other plant species.

\section{References}

1. Science, [http://www.sciencemag.org/] 